\title{
Anti-CD20/CD3 Monoclonal Antibody REGN1979
}

National Cancer Institute

\section{Source}

National Cancer Institute. Anti-CD20/CD3 Monoclonal Antibody REGN1979. NCI

Thesaurus. Code C119615.

\begin{abstract}
A bispecific, human monoclonal antibody with potential antineoplastic activity. AntiCD20/CD3 monoclonal antibody REGN1979 contains two antigen-recognition sites: one for human CD3, a T cell surface antigen, and one for human CD20, a tumor-associated antigen that is exclusively expressed on B-cells during most stages of B-cell development and is often overexpressed in B-cell malignancies. Upon administration, REGN1979 binds to both T-cells and CD20-expressing tumor B-cells, which cross-links the T-cells to tumor cells, and may result in a potent cytotoxic T-lymphocyte $(C T L)$ response against CD20expressing tumor B-cells.
\end{abstract}

